\title{
The Concept of Moral Obligation: Anscombe contra Korsgaard
}

\author{
MARIA ALVAREZ AND AARON RIDLEY
}

\section{Introduction}

A number of recent writers have expressed scepticism about the viability of a specifically moral concept of obligation, and some of the considerations offered have been interesting and persuasive. ${ }^{1}$ This is a scepticism that has its roots in Nietzsche, even if he is mentioned only rather rarely in the debate. More proximately, the scepticism in question receives seminal expression in Elizabeth Anscombe's 1958 essay, 'Modern Moral Philosophy',2 a piece that is often paid lip-service to, but-like Nietzsche's work-has only rarely been taken seriously by those wishing to defend the conception of obligation under attack. ${ }^{3}$ This is regrettable. Anscombe's essay is powerful and direct, and it makes a forthright case for the claim that, in the absence of a divine law conception of ethics, any specifically moral concept of obligation must be redundant, and that the best that can be hoped for in a secular age is some sort of neo-Aristotelianism. Anscombe is right about this, we think. And, among those who disagree, one of the very few to have taken her on at all explicitly is Christine Korsgaard, whose Kantianism of course commits her to the view that the concept of moral obligation is central, with or without God. Here, we try to show that Korsgaard loses the argument.

1 See, e.g., Bernard Williams, Ethics and the Limits of Philosophy (London: Fontana, 1993), ch. 10.

2 In Philosophy 33 (1958) 1-19; reprinted in Elizabeth Anscombe, Ethics, Religion and Politics: the Collected Philosophical Papers Vol III (Oxford: Blackwell, 1981), 26-42. Page references here are to the reprinted version.

For some interesting recent dicussions of this essay, although not for ones that make the points made here, see A. O'Hear, ed., Modern Moral Philosophy (Cambridge: Cambridge University Press, 2004). 


\section{Maria Alvarez and Aaron Ridley}

\section{I}

In her essay, 'Kant's Analysis of Obligation', ${ }^{4}$ Korsgaard is critical of a number of twentieth century philosophers, Anscombe among them. The structure of Korsgaard's criticism is, however, elusive. She rightly notes that in Anscombe's view the moral notions of 'ought' and 'obligation', which classical philosophers 'did very well without', are connected to a 'divine law conception of ethics, and, in the absence of that conception, lack sense. ${ }^{5}$ And it is natural to suppose that Korsgaard mentions this view precisely because she, Korsgaard, is engaged in elaborating and defending a conception of obligation-a Kantian conception - that seeks to give the notion of obligation sense without connecting it to a divine law conception of ethics. The natural supposition, therefore, is that Korsgaard mentions Anscombe's view in order somehow to disarm it; an end that is realised, she appears to hope, by aligning Anscombe with 'sentimentalist' moral philosophers-paradigmatically Hume-on the grounds that Anscombe shares with them 'an important assumption', namely, that 'the primary force of saying that I am obliged to do something is that I will be judged, punished, blamed, or will blame myself, if I do not'. Morality is thus constructed 'from the standpoint of the spectator or judge, taking the affections of approval and disapproval as the source of our most fundamental moral conceptions' 6 (call this sentimentalist assumption ' $\mathrm{S}$ ').

Korsgaard contrasts her own position with this, claiming that 'the focus on obligation' must come from 'an agent-centered (...) perspective, not from that of the moral judge. The primary deliberative force of saying "I am obliged to do this" is not "I will blame myself if I do not" but "my judgement that it is right impels me to do this"'(call this agent-centred view 'A'). And Korsgaard says that this agent-centred view 'is at least related to an older thought, which is found in the classical philosophers.' This thought captures one important feature of the way that moral action 'looks from the agent's point of view', namely, that an agent 'is moved to act by an ethical quality, a moral beauty and nobility, which he apprehends in the action' (call this Classical thought ' $C$ '). And this thought, she says, 'essentially drops out of sentimentalism', and is therefore-by implication-something that drops out of Anscombe's position too. ${ }^{7}$

4 In Christine M. Korsgaard, Creating the Kingdom of Ends (Cambridge: Cambridge University Press, 1996), 43-76.

Ibid., 50 .

Ibid.

Ibid., 50-51. 
If this is to work as a preemptive strike against Anscombe, at least the following three claims need to be true:

(i) Anscombe shares the sentimentalist assumption, S;

(ii) no one who endorses $\mathrm{S}$ can accept the agent-centred view, A; and

(iii) this agent-centred view, $\mathrm{A}$, is close enough to the Classical thought, $\mathrm{C}$, that $\mathrm{C}$, like $\mathrm{A}$, captures the "primary deliberative force of saying "I am obliged to do this"'.

If these three claims are true, Korsgaard will have what she wants: she will have shown that Anscombe, as an endorser of $\mathrm{S}$, cannot consistently acknowledge $\mathrm{C}$. And this matters because it is Anscombe's view that, in the absence of a divine law conception of ethics, our best bet is to return to Aristotle and to thoughts, precisely, like C. So if Korsgaard were right about all this, she could conclude either that Anscombe really is a sentimentalist about obligation, in which case her neo-Aristotelianism is doomed; or that Anscombe really is a neo-Aristotelian, in which case she already, and despite her apparent sentimentalism, acknowledges a sense of 'obligation' that is not connected to a divine law conception of ethics. And this dilemma would be fatal to Anscombe.

Assuming that this is Korsgaard's strategy against Anscombe, as it surely must be, our claim in this paper is that it cannot succeed. Indeed, if this is Korsgaard's strategy, it involves seriously misrepresenting Anscombe's position-a fact that is of more than local interest, since, as we shall argue, it betrays a fundamental weakness not only in Korsgaard's own position, but in the neo-Kantian project more generally, of which she is an acknowledged leader. In what follows, we shall defend that claim by aiming to show, first, that (i) is false: Anscombe does not endorse $\mathrm{S}$, and so that (ii), even if it is right, is irrelevant to her position; and second, that Korsgaard gives us no good reason to accept (iii), while Anscombe does give us good reason to reject it. In a final section we try to block Korsgaard's only obvious route of escape from the force of Anscombe's argument.

\section{II}

It seems clear that Anscombe does not endorse the sentimentalist assumption, that the 'primary force of saying that I am obliged to do something is that I will be judged, punished, blamed, or will blame myself, if I do not'. For Anscombe, as for Korsgaard, the notion of obligation is closely bound up with the notion of law, and for the former the notion of moral obligation, in particular, is 


\section{Maria Alvarez and Aaron Ridley}

bound up with that of divine law. ${ }^{8}$ But, although the notion of law is, in Anscombe's view, conceptually connected with that of a legislator, and perhaps with the notions of judgement and sanctions, this does not mean that the primary force of saying that I am obliged to do something is that I will be judged, punished, etc. (by God, by myself or by others). Rather, as Anscombe sees it, the primary force of saying that I am morally obliged to do something is simply that this action 'so described' is demanded by divine law and that, if divine law demands it, it follows, as a conceptual truth, that this the right thing to do full stop (i.e. regardless of the present appeal of the action or of whether any sanctions are attached to breaching that law).

Anscombe says that a law conception of ethics involves the idea that 'what is needed for conformity with the virtues (...) is required by divine law'. ${ }^{9}$ This means that the divine law conception of ethics involves the belief that there is perfect coincidence between what is right (what a fully and correctly developed virtue-ethics would dictate) and the dictates of divine law. And this is because, if one understands the concept of divine law, one understands that there cannot be a gap between what that law says and what it is right to do. That is precisely why Anscombe says that the man who believes in divine law will say "It is forbidden, and however it looks, it cannot be to anyone's profit to commit injustice". ${ }^{10}$ For this man, it is part of what it means to say that something is, e.g., forbidden by divine law, that it is something that it cannot be good for anyone to do. Such a man may or may not be able to apprehend 'a moral beauty and nobility' in the action that he is obliged to do, and he may or may not be moved to act by this beauty. But what matters is that for such a man the knowledge that this action is commanded (or forbidden) by divine law amounts to the knowledge that the action is right (or wrong).

Anscombe is, we think, unequivocal on this point, so it is surprising that Korsgaard should attribute to her the sentimentalist assumption, S. But perhaps Korsgaard has misunderstood what it is that Anscombe thinks survives the abandonment of belief in divine law. Anscombe says that the proper force of the notion of moral obligation vanishes in the absence of a divine law conception of ethics but she acknowledges that talk of moral obligation may retain 'the suggestion

8 Where, as will become clear in section IV, what matters above all is the structure of divine law, rather than its being legislated by God.

9 Anscombe, op.cit., 30.

$10 \quad$ Ibid., 42. 
of force' and may be 'apt to have a strong psychological effect' ${ }^{11}$ Consider Anscombe's analogy:

It is as if the notion of 'criminal' were to remain when criminal law and criminal courts had been abolished and forgotten. A Hume discovering this situation might conclude that there was a special sentiment, expressed by 'criminal', which alone gave the word its sense. ${ }^{12}$

This suggestion of force and its associated psychological effect are certainly bound up with notions of blame and guilt, with sentiments of approval and disapproval; sentiments that constitute the lynchpin of the sentimentalist moral system. But, so far, this is not enough to ascribe, as Korsgaard does, that common assumption to Anscombe and the sentimentalists. What Korsgaard would need to show in order to justify her claim is that both Anscombe and the sentimentalists believe that the force of the notion of obligation is rooted in sentiments of approval and disapproval, and that the main difference between them concerns, simply, whose sentiments are in play; e.g. that for Anscombe the relevant sentiments belong to the Legislator, i.e. to God, while for the sentimentalists approval and disapproval are the attitudes of men. But it is far from evident that this is a correct characterisation of Anscombe's position. For although Anscombe can admit that a belief in divine law requires a belief in a Legislator, and may involve a belief in judgement and punishment; and while she can admit that these beliefs may have a strong psychological effect on moral agents (of fear, of guilt, etc.), this does not commit her to the view that the main force of the notion of moral obligation in a divine law conception of ethics involves anyone's sentiments of approval or disapproval, including God's. It does not commit her, that is, to the sentimentalist assumption. After all, one can, if one has the requisite attitude to (human) laws, find deliberative force in the thought that something is illegal without having to have recourse to thoughts about the possible shame and pain associated with judgement and punishment. And what characterizes someone who has a divine law conception of ethics is, precisely, that he has that attitude — of reverence and respect-towards the divine law.

So much for Korsgaard's claim (i) - that Anscombe shares the sentimentalist assumption. She does not share that assumption. And, since she doesn't, claim (ii), even if it is true, must be irrelevant to her position.

12 Ibid., 30.




\section{Maria Alvarez and Aaron Ridley}

\section{III}

We now turn, therefore, to our second chief area of disagreement with Korsgaard, which concerns the third of the claims that we mentioned at the outset, namely, that the Classical thought, $\mathrm{C}$, is effectively equivalent to the agent-centred view, $\mathrm{A}$, and so that $\mathrm{C}$, like A, captures the "primary deliberative force of saying "I am obliged to do this".' Korsgaard's own grounds for making this claim are, it will be recalled, somewhat sketchy: she notes, merely, that A 'is at least related to' C. But unless 'at least related to' means 'is effectively the same as' her strategy against Anscombe collapses. So we have to understand her as claiming that A-'my judgement that it is right impels me to do this'-is effectively equivalent to $\mathrm{C}-\mathrm{my}$ apprehension in an action of 'an ethical quality' moves me to perform it-and that either of these formulations captures the "primary deliberative force of saying "I am obliged to do this".' But it is unclear why one should accept this. It is true that both formulations might be said to be 'agentcentred'-both, after all, tell us something about the way that things look 'from the agent's point of view'. But, and whatever one thinks about $\mathrm{A}$, it is far from obvious that $\mathrm{C}$, my apprehension in an action of an 'ethical quality', amounts to or implies 'I am obliged to do this', which is what Korsgaard requires. The necessary argument is missing.

And such an argument really is necessary, since Anscombe offers some powerful reasons for denying that $\mathrm{C}$ has anything to do with moral obligation at all. As we have already seen, Anscombe casts the Classical thought in terms of the virtues; and she observes that, on these terms, the fact that such-and-such an action would be, e.g., unjust is all by itself a reason not to do it. And this, she holds, in the absence of a divine law conception of ethics, gives the central remaining sense to the notions of 'ought' and 'obligation'-words that should be used, she suggests, 'in a non-emphatic fashion, and not in a special "moral" sense'. ${ }^{13}$ If we are to go down the neoAristotelian route, then, we cannot think about the morality of an action except by examining whether the action has some feature to recommend it, or the reverse-for example, that the action would be unjust, cowardly, etc.

This point is crucial to Anscombe's position. Indeed, it underwrites her rather striking claim that the modern moral philosophers whom she discusses in 'Modern Moral Philosophy' show signs of

Ibid., 38. 
'a corrupt mind'. ${ }^{14}$ Her contention is this. Suppose that one has given up on a divine law conception of ethics, but that one insists on holding on to the concept of moral obligation and its concomitant notions of 'morally right' and 'morally wrong'. Under these circumstances, she writes, it can appear to be 'legitimate'-although it is in fact corrupt- 'to discuss whether it might be "morally right" in some circumstances' to do something that is, as a matter of fact, unjust, such as 'procuring the judicial execution of the innocent'. ${ }^{15}$ And this appearance is generated by the fact that there can seem to be a gap between saying 'this is unjust' and 'this is morally wrong'. It can seem, that is, that 'if the term "unjust" is determined simply by the facts'-i.e. by what qualities an action has-it cannot be "the term "unjust" that determines that the term "wrong" applies'. Rather, or so it can seem, there must be something in addition, namely, 'a decision that injustice is wrong'. ${ }^{16}$ But such a gap, and the additional element needed to bridge it, only has a place, Anscombe insists, within a divine law conception of ethics; for here "it really does add something to the description "unjust" to say that there is an obligation not to do it; for what obliges is the divine law-as rules oblige in a game'. Without a divine law conception in place, by contrast, we have only a term, 'morally wrong', which, because it 'is cut off from the family of concepts from which it sprang', and which gave it its sense, 'both goes beyond the mere factual description "unjust" and seems to have no discernible content except a certain compelling force, which I should call purely psychological'. ${ }^{17}$

One important dimension of Anscombe's position, then, boils down to this: that if one is committed to the Classical thought, $\mathrm{C}$, that it is a sufficient reason to perform an action that one apprehend a certain 'ethical quality' in it, one adds nothing but a form of distracting (and misleading) psychological noise to one's claim by saying that one is 'morally obliged' to perform that action, or that the action is 'morally right'. And it follows directly from this that commitment to $\mathrm{C}$ must be incompatible with commitment to the agent-centred view, $\mathrm{A}$, since the latter view presupposes that there is some distinctive, i.e. additional, 'deliberative force' in saying 'I am obliged to do this' (of a sort that might be captured, for example, by saying 'my judgement that it is right impels me to do this'). Therefore, for Anscombe, the agent-centred view, A, and the Classical thought, C,

$\begin{array}{ll}14 & \text { Ibid., 40. } \\ 15 & \text { Ibid., 39-40. } \\ 16 & \text { Ibid., 40. } \\ 17 & \text { Ibid., 41. }\end{array}$




\section{Maria Alvarez and Aaron Ridley}

are not merely not effectively the same as one another, they are incompatible with one another, so that a commitment to $\mathrm{C}$ requires the repudiation of $\mathrm{A}$. Which means that if Anscombe's arguments are good, as we believe they are, the third of Korsgaard's claimswhich alleges that $\mathrm{A}$ and $\mathrm{C}$ come to the same thing-must be false.

But this, clearly enough, brings Korsgaard's own position under some pressure; for it requires her, if she wishes to retain the claim that there is some distinctive 'deliberative force' in saying 'I am obliged to do this', to abandon her commitment to the Classical thought, C. Furthermore, she must overcome the other important dimension of Anscombe's argument, namely, that if one is committed to talking of 'moral obligation' outside of the context provided by a divine law conception of ethics, one is required to introduce considerations concerning the 'moral' rightness and wrongness of actions that, first, go beyond any intrinsic features that those actions might have, and, second, show how the apprehension of those features gives rise to something extra, namely, to a sense of 'moral obligation', where that sense goes beyond the mere introduction of psychological noise-a requirement that Anscombe suggests cannot be met. Korsgaard needs to show us, that is, why we should reject Anscombe's principal conclusion-that in the absence of a divine law conception of ethics, the terms 'morally right' and 'wrong', together with the notion of 'moral obligation' to which they give the appearance of content, are redundant.

\section{IV}

We have noted, in the discussion of Anscombe's alleged sentimentalism, that Korsgaard does agree with Anscombe that the notion of 'moral obligation' requires a law conception of ethics. Part of the task that now confronts her, therefore, is to show how a distinctive, meaningful, sense of 'moral obligation' can be derived from a law conception of ethics that is, in the relevant sense, non-divine. For this, as we have seen, is something that Anscombe argues cannot be done. Korsgaard's preferred solution is Kant's, namely, that one must be understood as giving the law to oneself, as legislating for oneself-a suggestion to which Anscombe gives short shrift, characterising it as 'absurd'. For, she claims, 'the concept of legislation requires superior power in the legislator', just as the concept of a vote requires that there should be more than one voter (i.e. requires that more than one person be eligible to vote). ${ }^{18}$

18

Ibid., 27. 
The conclusion to be drawn from this, in Anscombe's view, is that, whatever we might do, there is nothing that we can do that is properly to be called 'legislating for oneself'. I cannot, she says, give the law to myself: 'whatever you do "for yourself" may be admirable', she writes: 'but is not legislating'. At most, I can frame my own rules of conduct. ${ }^{19}$ What is the difference? To regard something as a law is to regard it as something that has a certain authority over one-as something that provides a reason to act in a particular way, for example not to perform a certain kind of action, which is independent of any of the other reasons there may be for or against performing an action of that kind, and which is authoritative irrespective of such reasons. Whereas to frame one's own rules of conduct requires that those rules be, at least in principle, and if the whole process is not to be arbitrary, open to critical reflection (i.e. open to correction in the light, precisely, of reasons), in a way that is not true when what is at issue is the 'law'. So nothing helpful or illuminating is added by calling framing one's own rules of conduct 'legislating for oneself'. On the contrary, a level of obscurity about the status of those rules is introduced; and the effect of that, once again, is to leave the sense of 'moral obligation' that is supposed to have been derived from the process of self-legislation bereft of any obvious content.

But perhaps Anscombe is wrong about this, or over-states the case. Certainly Korsgaard would think so. Indeed, she develops a detailed account of what, in her view, self-legislation must involve, and of how it is possible. The central idea is as follows:

We might say that the acting self concedes to the thinking self its right to government. And the thinking self, in turn, tries to govern as well as it can. So the reflective structure of human consciousness establishes a relation here, a relation which we have to ourselves. And it is a relation not of mere power but rather of authority. And that is the authority that is the source of obligation. ${ }^{20}$

This does give $a$ sense to the notion of legislating for oneself. But in the present context it is also open to an obvious objection. For it is not at all evident that this conception of self-legislation is consistent with Korsgaard's espousal of A, the agent-centred view. On that view, recall, "The primary deliberative force of saying "I am obliged to do this" is (...) "my judgement that it is right impels me to do this".' Yet now there is a clear equivocation: for the ' $\mathrm{I}$ ' who is 'obliged' and the

Ibid., 37.

The Sources of Normativity (Cambridge: Cambridge University Press, 1996), 104. 


\section{Maria Alvarez and Aaron Ridley}

'me' who is impelled to 'do this' is the 'acting self'; whereas 'my judgement' refers to the judgement of the 'thinking self'. And this duality has the effect of returning Korsgaard to the structure, precisely, of a divine law conception of ethics (in which, as Anscombe has it, there is 'superior power' - or 'authority', if Korsgaard prefers— 'in the legislator'), a conception that Korsgaard can accept only on pain of admitting that the distinctive 'deliberative force of saying "I am obliged to do this"' is that the 'law' obliges 'me' (as 'acting self', as agent) 'as rules oblige in a game'. ${ }^{21}$

\section{Conclusion}

Korsgaard's strategy contra Anscombe was to try to place her in a dilemma, a strategy which, for the reasons we have given, fails. The upshot of that failure, however, is to place Korsgaard herself in a far severer dilemma. Anscombe's arguments leave Korsgaard with a choice. She can cleave, as she appears to want to, to the Classical thought, $\mathrm{C}$, that the apprehension of an 'ethical quality' in an action can properly, and all by itself, move one to perform it. Or she can cleave, as she also appears to want to, if not to A itself, then at least to the assumption underlying $\mathrm{A}$-namely, that there is some distinctive 'deliberative force' in saying 'I am obliged to do this'. If she chooses the first, she concedes that the notion of 'moral obligation' is indeed redundant. If she chooses the second, she concedes that that notion is empty unless one accepts a conception of ethics that is structurally identical, in the relevant respects, to the divine law conception. And either alternative, we suggest, is fatal to her position.

\section{University of Southampton}

21 In saying that Korsgaard is returned to the structure of a divine law conception of ethics, it should be clear that we are not claiming either that Korsgaard secretly believes in a divine legislator or that she would have to believe in one in order to rescue her position. Rather, our point is simply that, in introducing the distinction between legislator and agent (between 'thinking self' and 'acting self'), and in excluding the latter from the process of critical reflection that might result in the judgement, for example, 'this is right', she reduces the agent to a status incompatible with the agent's adopting the allegedly 'agent-centered (...) perspective' that Korsgaard endorses, and that we have labelled 'A'. And this leaves the agent standing in the same relation to the law (as laid down by the "thinking self') as the believer stands in to the law laid down by God-subject to something properly to be called 'obligation', to be sure, but not at all in the way that Korsgaard requires. 